\title{
'Biting the hand that feeds': Consumerism, ideology and recent animated film for children
}

\author{
Jillian Hinkins
}

\begin{abstract}
Animated film produced for children is a burgeoning industry. Since the days of the Disney monopoly, when feature length animated films were painstakingly hand drawn by a vast team of animation craftsmen, to the present time where technicians rely on computer animation technology, the volume of children's animated film has increased exponentially. It is an area that increasingly warrants careful and thorough investigation. In her article 'Monsters, Inc: Notes on the Neoliberal Arts Education' (2005) Elizabeth Freeman suggests that 'children's films are themselves "portable professors" of a sort, offering diagnoses of culture for adults even as they enculturate children' (p.85). Certainly animated film produced for children can provide a window for examining societal structures and cultural practices by the adult audience, whilst at the same time instructing and guiding children in regard to an understanding of themselves and their place in the society that they inhabit. Indeed, implicit and explicit ideologies in children's animated film are likely to inform both adult and child audiences, promoting certain beliefs and assumptions and shoring up idealized goals and expectations. There is also a sense in which explicit and embedded ideologies are being knowingly transferred from one generation to the next. In this way, children's film can provide a sense of continuity and of clarification, performing a pedagogic function with regard to a myriad of issues.
\end{abstract}

In the introduction to his book, Language and Ideology in Children's Fiction (1992), John Stephens claims that 'writing for children is usually purposeful, its intention being to foster in the child reader a positive appreciation of some socio-cultural values which, it is assumed, are shared by author and audience' and can involve 'an attempt to perpetuate certain values or resist socially dominant values which particular writers oppose' (p.3). In a similar way, filmic texts produced for children are usually didactic in nature, often overtly addressing particular issues and behaviours and providing directives to both the child and adult audiences as to how such issues or behaviours should be regarded or responded to. Such didacticism can be appealing to the adult audience as it provides moral certainty and external authority, thereby supplementing the parental role of educating and guiding children as well as defining and shaping value stances for adults to adopt. The advent of video and DVDs also means that children's films are seen, and their ideologies absorbed, not just in the theatre, but in the home, where purchased films can be repeatedly viewed in a similar way to a favourite book being read over and over again. However, despite the central role of the transference of ideology, and regardless of whether such a process is intentional or not, the ultimate aim of the corporately produced children's animated film is to create money, resulting in a profit. It is the intention of this paper to explore the impact of consumerism on recent children's animated film, with a particular emphasis on some of the ways in which the medium is constructed in order to sell itself, and the effect that ideologies of consumption can be seen as having on the ideologies both embedded in and overtly conveyed through filmic texts in general and including a close analysis of Dreamworks' 2006 animated film Over the Hedge.

\section{Consumerism}

The role of consumption and the ideology of consumerism are key elements in modern global cultures and societies, and are increasingly the subject of academic investigations. They are also emerging as incidental elements and central themes in recent animated films produced for children. Dreamworks' Over the Hedge (2006) takes consumerism as one of its central themes and overtly tackles many of the issues associated with it, but consumerism is also a key element in Disney/Pixar's Cars (2006), Monster's, Inc. (2001) and Toy Story 1 and $2(1995,1999)$ as well as being incidentally addressed in films such as Pixar's $A$ Bug's Life (1998), Dreamwork's Antz (1998) Shrek (2001), Shark Tale(2004) and Disney/Pixar's The Incredibles (2004) amongst others. Even when such films appear far removed from modern Western societies (e.g. being set in an insect colony, underwater, a fairy tale world or the future, and involve non-human protagonists such as ants, superheroes, fairytale characters, cars, fish or animals), there are nevertheless constant references to modern Western ways of being and current beliefs and fashions, and often these relate specifically to consumerism and consumption. Kenway and Bullen state in their book Consuming Children (2002): 'there is a new way of being, the consumer, and a new kind of ideology, consumerism'(p.10). Such a view would 
appear to be supported by the growing interest in exploring aspects of consumerism in recent animated children's film, as evidenced by current reoccurring motifs referencing consumption and thematic engagement with consumerism itself. Freeman's notion of children's animated films being like "portable professors" suggests that the film industry will reflect those issues and interests which the audience will most readily engage with and be most concerned about; children's films are in one sense, then, akin to being a finger on the societal pulse. At the present time, consumerism is one such issue under review.

Market forces which have enabled the emergence of consumerism have long been the subject of considerable debate. For many, market forces are regarded as being a naturally regulating, positive force, with an innate rationality that can be relied upon to produce ultimately positive outcomes in the consumer's favour (Kline 1993, p.1). By way of contrast, Kenway and Bullen suggest that those adhering to a 'production of consumption' theory warn that market forces are ultimately manipulative and controlling, resulting in entrenched inequalities, being destructive of local communities and being responsible for negative individual behaviours associated with individualism and materialism (Kenway \& Bullen 2002, p.14). Whether for good or ill, market forces and the consumerism which accompanies them are deeply entrenched in the modern way of being and are a guiding force in the moulding or shaping of society at the present time.

Much of the current preoccupation with consumerism can also be traced to underlying anxieties regarding the changing nature of modern Western society and the economic drivers underpinning such change. Needs-based production has been largely replaced by an industry that caters instead to desire, and much of that industry is concerned with moulding and producing a consumer identity fixated on rapid and constant consumption. Zygmunt Bauman(2002) suggests that modern consumerism is no longer just an individual's means of distraction but is, in fact, a 'socially constructed lot' and 'a way of life (indeed the only common one) available to all' and argues that in the move away from production relating to need to production relating to desire and wish, the ultimate product has become not the article to be consumed but the consumer themselves (p.182). Such rapid and significant change in consumer behaviour has produced a sense of unease and societal dislocation which has in turn fueled a desire to isolate and understand consumer ideology; to replace uncertainty and shifting values with clear directives and moral certainty. The fact that consumerism no longer appears to be wedded to underlying and shared values such as needs-based consumption, frugality and self-control has a tendency to engender a desire in many to enunciate clear explanations and moral guidelines; there is a sense of wanting to regain individual control over a powerful and rather unsettling societal influence.

A large part of this concern also stems from the fact that consumption and consumerism are perceived as having a particular impact on the young. As Kline states "consumption is now a central part of the "matrix of forces" that socialize young children; just as central as family, school and life' (in Kenway and Bullen 2002, p.37). This leads to concerns regarding the exact nature of media culture and the underlying intentions of the concentrated group of companies who are largely responsible for its production. As Murdock and Golding claim in Norma Pecora's book The Business of Children's Entertainment (1998), mass media are 'first and foremost industrial and commercial organisations which produce and distribute commodities'(p.3) and have little incentive to devote their resources towards generating what Robert W. McChesney describes as positive 'externalities', that is, by-products or outcomes not connected with profits (Von Feilitzen et al., 2002, p.23)

Consumerism is thus not only an area of interest explored by, and featured in, many children's films, it is also a primary influence upon the film industry itself. The financial benefits resulting from the manufacture and sale of animated film for children are immense. This is due in part to reduced production costs as a result of computer animation techniques, as well as other factors such as the ongoing sale of DVDs and videos, a complementary industry based on the sale of merchandise associated with film and the sale of character licensing deals. It is also due to an increasing awareness of the child as a lucrative section of the overall market, and the film industry is just one part of the wider media industry that is increasingly interested 
in the economic potential of the child. As McChesney suggests, attracting children to commercial media and to commercial messages is now a major industry (Von Feilitzen, Cecilia, Carlson and Ulla eds 2002,p.28) and the film industry, like so many others, has resorted to a wide range of strategies which are devised and implemented in order to attract and retain the child as consumer. There is thus an economic imperative behind the phenomena of the film industry, where the needs of the advertiser outweigh the needs of the audience (Von Feilitzen, Cecilia, Carlson and Ulla eds 2002, p.26). Not only this, but social and political outcomes can be harnessed in the construction of the child audience as a commodity, shaping the child in a way that will benefit the producer.

Adults are also targeted, especially with regard to younger children, for the film produced for the child must also appeal, at least in part, to the adult who by and large finances the purchasing of the ticket, DVD or other related products. The film industry has also been quick to take advantage of what Anthony Giddens suggests is a loosening of tradition and heritage leading to a rise in 'creating one's own narrative', which in turn has prompted a growing level of uncertainty and the possibility of increased parental anxieties (Gauntlett 2001, p.1). Such anxieties are easily targeted and manipulated in order to promote a consumer product. Bauman claims that 'uncertainty-generated anxiety is the very substance that makes individualized society fertile for consumerist purposes' (Bauman 2002, p. 199). In terms of the children's film industry, parents are keen to see films which address their specific fears and which provide solutions or clear direction on how to best manage those fears, providing a positive message for their children.

However, adults are not just being targeted in terms of their role as gatekeeper for the child. In recent years, animation has gained an aura of adult respectability, due in part to the success of television shows such as The Simpsons, Futurama and South Park which have addressed broader issues than those previously associated with animation, and included jokes, political and historical asides, and iconic references specifically for the adult audience (McDonnell 2001, p.87). In terms of major film releases, the surprising success of the Star Wars series in the 1970s, with its emphasis on sequels and associated merchandising as well as its box office appeal to an adult audience (particularly surprising, as it had been originally targeted at 12-14 year old males) paved the way for the development offilms aimed at an increasingly dual audience (Pecora 1998, p.122). In the animated film industry, the inclusion of elements such as a popular music score (The Little Mermaid, Beauty and the Beast, The Lion King), contemporary witticisms and big-name voice actors (Aladdin, Monsters, Inc., Shrek and Shrek 2), the inclusion of well known popular songs (Shrek and Shrek 2, Cars) and the positive endorsement of such recent animation successes by film critics cemented the notion that animation could be as successful with adults as with children. Such a trend has proven to be a marketing dream, with the child audience being attracted, not alienated, by the appeal of sophistication and the adult audience increasing exponentially. The industry's increasing interest in the segment of the film market which produces children's animation is evidenced by the rise in animation production companies, resulting in what Kathleen McDonnell describes as 'the Animation Wars of the late 90's' and the ever increasing number of animated films presently on offer (McDonnell 2001, p.79).

One other area of change noticeable in many recent animated films for children which may appeal to both the adult and child audience, is the revisionist, subversive or transgressive look or feel of the film, conveying a sense of being radical, new, or cutting edge. A particular aspect of consumer ideology is the desire for something new. As Marilyn Halter claims 'novelty is, perhaps, the most significant characteristic of modern consumer capitalism' (2000, p.8). In terms of children's animated film, this means a rapidly changing procession of filmic products and accompanying merchandise which are viewed and purchased because they are 'the next big thing' and which are perceived as having the most cutting-edge technology and visual effects as well as the most recent look, feel and contemporary comment. The use of popular and current media personalities for voice- overs does much to convey a sense of the film being contemporary and relevant, as does the frequent use of intertextuality, building a myriad of bridges between the animated film and the other elements of media and popular culture which it references. 
Dreamworks' Over the Hedge works precisely in this way when the Persian cat screams out 'Stella!', reminiscent of Marlon Brando's performance in A Street Car Named Desire and when the possum father whispers 'Rosebud' during his artistic death scene, thereby bringing, at least to the adult mind, the major plot device of Orson Well's Citizen Kane.

A large degree of the appearance of 'newness' in recent animated film is also achieved due to the use of techniques such as the carnivalesque, the taboo and scatology. Shrek, for example, is peppered with visual and verbal gags relating to bodily functions, with its central storyline being driven by playful reworkings of and divergences from a traditional fairytale plot (e.g. an ogre is the reluctant hero). Historically these devices have been used to subvert and overturn; however, the growing frequency of their usage and thus familiarity has tended to lessen their impact in recently produced children's animation. It is also lessened by an association of such techniques with official sanctioning due to the nature of the large corporations which are responsible for their production and the role of parental approval in taking their children to these movies or allowing them to go. The use of such methods is very much a marketing strategy, with an intention to entertain rather than seriously challenge official ideologies. Shrek, for example, can be seen as ultimately supporting patriarchal ideology rather than offering any real alternative, as argued by Maria Takolander and David McCooey (2005). In many cases, therefore, the appearance of 'newness' and difference in recent animated filmic texts for children is actually the result of marketing strategies and consumer technique; the ability to produce an up-date version, to appeal to the voracious desire for the new (and the consumer compulsion to be rid of the old) whilst in fact retaining much of the essentials of the original.

\section{Over the Hedge: consumerism in the spotlight}

Several recent animated films for children have specifically targeted consumerism in Western society for close critique, promoting various values and directives as they expound this theme, attempting to address and partially alleviate parental fears and anxieties. DreamWorks' recent 2006 animated offering, Over the Hedge, is particularly interesting in the way that it uses the film as a medium for explaining society, particularly consumer society, as typified by middle-class suburbia. It is overtly didactic and presents as almost an instruction manual on how to recognize and avoid various pitfalls in consumer society. This is achieved by directing the film's action from the point of view of small woodland creatures who are viewing human suburban lifestyle from an outsider's perspective. This point of view is also a completely fresh one; these creatures appear to never have been exposed to aspects of consumer life previously, with the exception of RJ the raccoon who knows how to use a food vending machine and who has already tasted and succumbed to the allure of 'Spuddies' chips. Indeed, there is a consistent message throughout the film that the dangers of consumerism are akin to the dangers of illicit drugs, with RJ portrayed as an addict.

In the first moments of the film, nothing can be seen and only a sound, which is recognizable as the sound of money clinking, can be heard. After a short delay the visual emerges, and it can be seen that the sound emanated from coins being dropped into a vending machine. The opening scene is of a small raccoon, dwarfed by the metal and glass vending machine, frustrated in its repeated and increasingly angry efforts to extract the last packet of Nacho corn chips from the machine. From its first moments, then, the tone of the movie is clear: money is a significant element, consumer products are alluring and desirable but often frustratingly unobtainable. The gleam of the consumer marketing machine offers much but ultimately may fail to deliver. The scene also goes on to include RJ scrounging in overflowing rubbish bins, searching for food amongst the waste, thereby drawing attention to the fact that casual and wasteful disposal and the pollution of natural surroundings as well as the natural inhabitants, are inevitably part of an urban, consumerist culture. It draws attention to one of the defining elements of consumer culture, being the desire to dispose as well as the desire to acquire.

The following scene, where RJ faces the dangers of the hibernating bear's cave in order to obtain food, leads to the emergence of a second and dominant theme in the film: the harmful and addictive nature of greed. When RJ enters the cave he easily obtains what he came for: a single packet of Nacho Corn Chips. However, he is quickly tempted by 
the sight of many other food items. Muttering what sounds like a well-worn mantra, 'just take what you need', he attempts to leave, but cannot resist going back for more and more, including a red wagon and blue esky to carry the enormous mound of food. His final undoing is when he goes back for one last packet of 'Spuddies' entwined in the bear's arms, and awakens the bear, not by stealing the can but by succumbing to greed and opening it straight away, alerting the bear to his presence by the sound of the vacuum sealed pack opening. The message is clear: succumbing to greed leads on to greater and greater over-consumption, with desire far out-weighing actual need and resulting in punishment. Such ideology resists what Bauman suggests is a current trend towards 'the new plasticity of needs' where consumption is no longer aligned with need or function and no longer needs to 'justify itself by reference to anything but its own pleasurability', and provides an alternative whereby ethical issues are again related to consumption, and to consume too little is poverty and too consume overly much is greed (Bauman 2002, p.183).

Throughout the film, Vincent the grizzly bear is the embodiment of greed, the dangerous untamable creature who will rightly claim anyone who begins to toy with the temptation to take more than they actually need. Greed in the form of Vincent is the physical form of selfish ambition, coupled with the desire to succeed as an individual without taking any group or corporate responsibility. Near the conclusion of the film, when RJ has managed to escape with the goods that Vincent requires, but only at the cost of sacrificing his friends, Vincent the bear comments:

"What a vicious, deceitful, selfish thing. You take the food and they take the fall. You keep this up and you'll be just like me - having everything you want".

Becoming the bear, individual, selfish and greedy, is presented as the worst possible outcome, and RJ is presented as reaching a redemptive moment when he declares "I had everything", referring to the more intangible qualities of friendship and family values of commitment, unconditional love and support, rather than the physical products of consumerism. For the rest of the film he attempts to associate himself with the woodland animals, seeing himself as part of their group rather than as an isolated, independent individual. As RJ is the chief focaliser of the story, the audience is therefore directed to adopt his view point and to applaud his change of heart. His sentiments are encapsulated in the comment: "This is the gateway to the good life: the family".

In addition to the concept of greed, throughout the film other aspects of suburban consumer life are discovered and explored by the woodland creatures. At first urban life appears unintelligible to them, such as when Vern the tortoise investigates a suburban backyard and either misunderstands or is physically threatened by what the audience would perceive to be natural and normal elements of suburban life. It is RJ the raccoon who interprets and explains the suburban landscape to the other animals, and although the audience is aware that RJ has ulterior motives and cannot be trusted, he does emerge as knowledgeable and perceptive with regard to understanding not just objects in the new landscape ("54 acres of man-made paradise") but also the psychological and economic structures underpinning it. He describes the suburban lifestyle as one which revolves around food, saying 'We eat to live, they live to eat' and goes on to describe the lengths that humans will go to in order to procure food, ultimately claiming 'They worship it'. Finally he declares that 'they don't have enough - enough is never enough', despite the obvious over-abundance in the urban, consumer lifestyle. Such a statement about the humans, although it is made by a character for whom enough is also not enough, still serves to highlight the flaws of consumer life and to encourage the audience to side with the animals who are in a position to judge for themselves the folly of such behaviour by being in the role of on-lookers rather than participants. When one of the mothers in the suburban landscape tells her distressed children to 'go inside, have a cookie, turn on the TV and calm down', the audience, particularly the adult members of the audience, registers that such advice only perpetuates a consumer lifestyle where bodily satisfactions and distractions such as television dull an individual's ability to question or attempt to alter their circumstances.

Over the Hedge ostensibly encourages resistance to the traps of consumerism rather than just succumbing to its wiles. When RJ first interprets the new urban landscape to 
the forest creatures, he describes it as 'all good'; he is the ultimate salesman, pressing his quarry in order to make a sale, deliberating avoiding negative aspects of his product that may potentially hinder a transaction taking place. His character highlights one of the first rules of survival in the consumer world: don't believe everything that you are told. In the early stages of the film, RJ shows the animals a map and points out that there are many kilometers of suburbia and only a tiny portion of woodland; he comments 'this tiny speck is you'. There is a sense of being under siege and overwhelmed by the urban spread and its accompanying goods, possessions and lifestyle. By the end of the film, however, the animals are resistant and wiser, defending not only their persons but the woods itself. There is a sense that resistance has purpose and that individuals can form corporate bodies which can in turn effect outcomes.

The urban world and its accompanying consumer lifestyle are, however, shown to be a powerful and formidable force, not just in physical size but in their ability to seduce and to entice. A pivotal moment in the film is when the animals have declined to help RJ, and in his efforts to recruit their help, he exposes them to something akin to a drug: he opens a packet of Nacho corn chips. The resulting explosion is shown as being equivalent to the detonation of an atomic bomb: the orange nacho flavoring explodes out of the packaging forming a mushroom cloud, which is so large that it can be seen from outer space. The implication is plain- just like the first atomic explosions, this moment is cataclysmic on a global scale, and there will be no return; the world of the animals is irrevocably changed and the effects of exposure to the corn chips will linger, influencing their lives long after the mushroom cloud has died down. They quickly acquiesce to RJ's plans in order to secure more of the corn chips; their willingness to help is a down payment on future gastrological pleasures. The message to the audience is clear, and it is one that is repeatedly presented throughout the film: the artificial flavors and forms of consumer life are corrupting and addictive; one must be savvy and smart, quick to discount external or immediate rewards and aware of marketing tricks and traps to survive in the consumer world.

Over the Hedge is just one of many recent animated films which proffer analysis of and methods for dealing with aspects of consumer society. Despite a concerted effort by these recent films to critique consumer ideology and warn against the traps and pitfalls of consumer society, an interesting aberrance can be seen to occur in relation to underlying messages, what Stephens refers to as implicit ideologies and Louis Athusser refers to as the 'obviousnesses' of a society (cited in Nodelman \& Reimer 2003, p.80). In this way it can be seen that there is often a tendency in such films to self-subvert by sending secondary, often contradictory, messages regarding consumerism which are embedded in the texts. Therefore, although the overt message of Over the Hedge is to be wary of consumer ideology and to remain removed and critical of consumer behaviours, there are several implicit assumptions which negate this point of view. First is the undeniable appeal of the products themselves. Although the central message of the film is to avoid being greedy, the protagonists are ultimately unable to resist the bodily pleasures that are tempting them. Hammy obviously enjoys his caffeine drink, which has the effect of sending him into a sort of drug-induced stupor, whilst all the animals are joined in the closing scene of the film after the credits in trying to retrieve Nacho Corn Chips from a vending machine. Consumer products may be chemically enhanced and potentially hazardous, but they are also pleasurable.

In addition, although the film overtly encourages the notion of resistance to the consumer machine, its implicit assumption is that it is only by becoming immersed in consumer culture can the animals survive. It is not by resisting consumer goods and remaining separate that the animals are able to escape being destroyed by the dangers of both suburbia and the woods: the pest control man known as the 'Verminator', as well as Vincent the grizzly bear. Instead, it is only by being completely immersed in consumer culture that they acquire the skills to survive. The hedgehog children are able to drive the van to safety because they have become experts at playing Autohomicide 3 on their electronic Gameboy toy; RJ can only keep Hammy focused on his task by using an electronic red dot light beam to lead him; the animals are saved from impending destruction because Hammy is given a Maci-B caffeine drink, thereby enabling him to move at super-speed; finally, when both the pest control man and the bear are captured 
by the illegal 'de-pelta turbo' machine, the animals protect their eyes with a variety of consumer products, ranging from $3 \mathrm{~d}$ glasses, helmets and buckets through to heart shaped sun-glasses. It is the very skills and objects acquired from within consumer society that ultimately enable them to survive. As Stephens suggests, it is the ideology which is implicit that may have a more powerful impact on its audience, claiming that the 'implicit, and therefore invisible, ideological positions are invested with legitimacy through the implication that things are simply 'so"(Stephens 1992, p.84). Potentially, then, the implicit messages regarding consumerism in Over the Hedge may carry more weight than those which are explicit and overt.

It would appear that, ultimately, didacticism is successful as a marketing strategy in harnessing parental approval in both the initial selling stages of the film and DVD, as well as in linking positive attitudes towards its narrative with the ownership of other merchandising objects, such as food, clothing and toys. Interestingly, however, messages which appear to promote certain desirable values and attitudes, thereby gaining parental approval, can also be accompanied by implicit assumptions and attitudes which may run counter to its primary didactic text. In this way, a film that overtly promotes consumer savvy behaviour and which explicitly warns against naivety in consumer issues can also be a vehicle for the promotion of aspects of consumerism, thereby sending contradictory messages. In addition, all recent animated children's films produced by such corporate giants as Disney/Pixar and Dreamworks, despite advocating consumer awareness and criticism of the consumer system have also attempted to take advantage of a positive audience response to the inclusion of such values in its narrative by allowing for the promotion of the sale of innumerable short-lived consumer products which are a by-product of the film, and vigorously cross-promoting their films through the internet and other media outlets in the hopes of increasing profits.

\section{Conclusion}

Consumerism in animated film produced for children will always be a key element. Foremost, film is a commodity and is therefore filled with various strategies and techniques employed by its producers to attract and maintain an audience, with profit as its ultimate goal. There is an inbuilt tendency in these films to cultivate the child as a consumer. In addition, filmic text is embedded with ideologies and often has specific didactic intentions. Such ideologies, both overt and implicit, are often confused and even contradictory, with many films having a tendency to self-subvert their more overt messages. Much of this ideology, whether intentionally or not, is driven by a consumerist agenda. By and large, animated children's films tell audiences what they want to hear and entertains them in the way they want to be entertained, because this is the way they are willing to part with their money, both at the box office, in the DVD store and in countless supporting merchandising opportunities. What appears to be subversive, transgressive or revisionist is often selfsubversive and only superficially tinkering with criticism and is, in fact, delivering a fairly consistent message in support of the status quo and modern consumer society. Rather than threatening the institution of consumerism and the behaviours associated with consumption, many recent filmic texts, whilst endeavouring to appear radical and new, are staunch supporters and advocates of the institutions which produced them. This paper has examined one recent film, Over the Hedge, as a way of demonstrating how various strategies and methods can be used to engage an audience in promoting a message about the pitfalls of modern consumer society, while at the same time subverting that message. Though characters may engage, playfulness entertain and technologies dazzle, Over the Hedge is shadowed by corporate and consumerist ideologies.

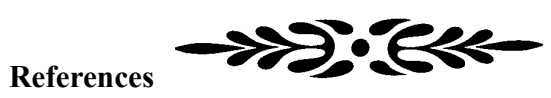

A Bug's Life (1998) Pixar. Directors John Lasseter, Andrew Stanton.

Aladdin (1992) Walt Disney Co. Director Ron Clements.

Antz (1998) Dreamworks. Director Eric Darnell.

Bauman, Z. (2002) Society Under Siege. Maldon, MA, Blackwell. 
Beauty and the Beast (1991) Walt Disney Co. Directors Gary Trousdale, Kirk Wise.

Cars (2006) Disney/Pixar. Director John Lasseter

Freeman, E. (2005) 'Monsters, Inc: Notes on the Neoliberal Arts Education' New Literary History 36: 83-95.

Gauntlett, D. (2001) 'Anthony Giddens: lifestyle’: http://www.theory.org.uk/giddens6.htm. (Accessed 24 November 2004).

Halter, M. (2000) Shopping For Identity: the Marketing of Ethnicity. New York, Random House.

The Incredibles (2004) Disney/Pixar. Director Brad Bird.

Kenway, J. \& Bullen, E. (2002) Consuming Children. Berkshire, Open University.

Kilne, S. (1993) Out of the Garden: Toys and Children's Culture in the Age of TV Marketing. London, Verso.

The Lion King (1994) Walt Disney Co. Directors Roger Allers, Rob Minkoff.

The Little Mermaid (1989) Walt Disney Co. Directors John Musker, Ron Clements.

McDonnell, K.(2001) Honey, We Lost the Kids: Re-thinking Childhood in the Multi-Media Age. Toronto, Ontario, Pluto Press.

Monster's, Inc. (2001) Disney/Pixar. Director Peter Docter.

Nodelman, P. \& Reimer, M. (2003) The Pleasures of Children's Literature $3^{\text {rd }}$ edition. New York, Pearson Education.
Over the Hedge (2006) Dreamworks. Directors Tim Johnson, Karey Kirkpatrick.

Pecora, N. O. (1998) The Business of Children's Entertainment. New York, Guilford Press.

Shrek (2001) Dreamworks. Directors Andrew Adamson, Vicky Jenson.

Shrek 2 (2004) Dreamworks. Director Andrew Adamson.

Stephens, J. (1992) Language and Ideology in Children's Fiction. London, Longman.

Takolander, M. \& McCooey, D. (2005) 'You Can't Say No to the Beauty and the Beast: Shrek and Ideology', Papers 15: 5-14.

Von Feilitzen, C. \& Carlson, U. (eds) (2002)

Children, Young People and Media Globalisation. Goteborg University, Sweden: The UNESCO International Clearing House on Children, Youth and Media.

Toy Story (1995) Disney/Pixar Director John Lasseter.

Toy Story 2 (1999) Disney/Pixar Director John Lasseter.

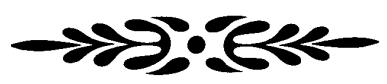

\section{BIOGRAPHICAL NOTE}

Jill Hinkins gained her BA and Dip Ed at Monash University. She completed her MA (Writing and Literature) in 2006 at Deakin University and has a particular interest in ideology and children's film animation. 